\title{
Promoting Self-Learning and Autonomy with the Use of ICT in Higher Education Through Projects Close to Professional Practice
}

\author{
Carlos R. Jaimez-González ${ }^{1} \&$ Wulfrano A. Luna-Ramírez ${ }^{1}$ \\ ${ }^{1}$ Department of Information Technology, Metropolitan Autonomous University, Cuajimalpa Campus, Mexico \\ Correspondence: Carlos R. Jaimez-González, Department of Information Technology, Metropolitan Autonomous \\ University, Cuajimalpa Campus. Av. Vasco de Quiroga 4871, Santa Fe Cuajimalpa, C.P. 05370, Mexico City, \\ Mexico.E-mail: cjaimez@correo.cua.uam.mx
}

Received: October 15, 2018

Accepted: December 16, 2018 Online Published: February 25, 2019

doi:10.5539/jel.v8n2p37

URL: https://doi.org/10.5539/jel.v8n2p37

\begin{abstract}
This paper presents an academic experience about the incorporation and appropriation of various ICT in four courses of the undergraduate program in Information Technologies and Systems of the Metropolitan Autonomous University in Mexico. These courses present students' situations close to professional practice by performing a specific role to solve problems in a particular area or project. They aim to develop the capabilities of integration and use of knowledge and skills that students have acquired in the curriculum. The paper presents the organization and structure of the courses, their content, ways of conducting and evaluation, as well as some examples of projects that have been supervised by the authors. It also describes in detail the process of conducting a project carried out with students, the ICTs that were incorporated and the possibility of innovation that the teacher has by managing these types of projects. This paper also shows the potential of the courses in the training of students, by promoting autonomy with the use of ICT, involving them in the improvement of their skills for the analysis and use of information, and fostering self-learning through situations and experiences close to their professional practice. Additionally, this experience reinforced students' critical thinking by promoting the ability to judge different software products, as it allowed them to identify problems and find their solutions, become familiar with programming languages and develop their oral and written communication skills.
\end{abstract}

Keywords: educational innovation, ICT, professional practice, higher education, academic experience

\section{Introduction}

The Metropolitan Autonomous University, Cuajimalpa Campus (UAM-C), located in Mexico City, offers the undergraduate program in Information Technologies and Systems (ITS), in which the study program is composed of a series of courses called Teaching-Learning Units, among which are the Thematic Laboratories. They aim to develop the ability of students to integrate and use the knowledge and skills acquired so far to take a specific role to solve problems of a particular area or project close to their professional practice.

The thematic laboratories open a space in which teachers can innovate in education and incorporate a series of information and communication technologies (ICT) to develop a project similar to those that future graduates will find in their professional practice. The potential of the thematic laboratories is wide, because they allow to promote students' autonomy with the use of ICT, involving them in perfecting their skills for the analysis and use of information, and promoting their self-learning with situations and experiences close to their professional practice. In addition, because the thematic laboratories are carried out in groups of students, it is promoted the solution of collective situations, in order to develop attitudes of responsibility through teamwork.

The rest of the paper is organized as follows. Section 2 presents the structure and organization of the thematic laboratories, which explains their objectives, relevance and level in the ITS undergraduate program of the UAM-C (UAM-C, 2018a), as well as the skills that students are expected to develop. Section 3 is intended to describe the content of the laboratories, as well as the way in which they are currently conducted and evaluated. To illustrate the types of projects and the topics that have been addressed in the thematic laboratories, section 4 provides a list of four examples of projects that the authors have supervised. Section 5 deals with the experience of a project carried out by students in a thematic laboratory, supervised by the authors of this paper, which describes the different stages of the process to develop it, as well as the ICT that were incorporated in each of the 
stages. In the same section, the virtues of technological incorporation in this type of course are discussed, where their use is fundamental to carry out the project successfully. Finally, conclusions are provided in section 6 .

\section{Structure and Organization of the Courses}

Thematic laboratories are four courses that belong to the ITS undergraduate program of the UAM-C (UAM-C, 2018a), which is organized in twelve terms, with a duration of eleven weeks each, and structured in three levels: the first level, called the general level of initial training, which includes the first term; the second level or basic training, is composed of the courses of the terms II to VII; and finally, the third level, called professional training, includes the courses of the terms VI to XII. The four courses discussed here, Thematic Laboratory I, II, III and IV, are part of the second and third levels and are taught in terms V, VI, VII and VIII, respectively, as can be seen in the curricular map of Table 1.

Table 1. Information technologies and systems undergraduate program

\begin{tabular}{|c|c|c|c|c|c|}
\hline \multirow[t]{2}{*}{$\mathrm{I}$} & Mathematics & Language and & Mathematical & Seminar on & \\
\hline & Workshop & Argumentation & Thought & Sustainability & \\
\hline \multirow[t]{2}{*}{ II } & Discrete & Structured & Static Web & History of & \\
\hline & Mathematics I & Programming & Programming & Computer Science & \\
\hline \multirow[t]{2}{*}{ III } & Discrete & Data & Computer & Communication, & \\
\hline & Mathematics II & Structures & Architecture & Design and IT & \\
\hline \multirow[t]{2}{*}{ IV } & Logic and Logical & Object-Oriented & Operating & Administrative & \\
\hline & Programming & Programming & Systems & Theory & \\
\hline \multirow[t]{2}{*}{ V } & Probability and & Analysis and Design & Network & Management of & Thematic \\
\hline & Statistics & of Algorithms & Architecture & IT Systems & Laboratory I \\
\hline \multirow[t]{2}{*}{ VI } & Theory of Formal & Databases & Distributed & Human Behavior in & Thematic \\
\hline & Languages & & Systems & Organizations I & Laboratory II \\
\hline \multirow[t]{2}{*}{ VII } & Artificial & Dynamic Web & Security & Human Behavior in & Thematic \\
\hline & Intelligence I & Programming & Seminar & Organizations II & Laboratory III \\
\hline \multirow[t]{2}{*}{ VIII } & IT Systems & Human-Computer & Network Design & Systems & Thematic \\
\hline & & Interaction & and Installation & Integration & Laboratory IV \\
\hline IX & & & Mobility & & \\
\hline \multirow[t]{2}{*}{$\mathrm{X}$} & Optional & Optional & Optional & Terminal & \\
\hline & Orientation & Orientation & Integration & Project I & \\
\hline \multirow[t]{2}{*}{$\mathrm{XI}$} & Optional & Optional & Optional & Terminal & \\
\hline & Orientation & Integration & Integration & Project II & \\
\hline \multirow[t]{2}{*}{ XII } & Optional & Optional & Optional & Terminal & \\
\hline & Orientation & Integration & Integration & Project III & \\
\hline
\end{tabular}

The main objective of the thematic laboratories is that students integrate and use the knowledge and skills acquired so far to take a specific role to solve problems in a particular area or project, close to their professional practice. With respect to the specific objectives, it is expected that students will be able to: 1) develop their teamwork skills by project; 2) contribute to the development of their capacity to integrate knowledge around clear objectives embodied in a work plan; 3 ) develop their responsibility and creativity in a work environment similar to that of a small organization specialized in the topic assigned to the laboratory; and 4) contribute to the development of their ability to communicate orally and in writing. These objectives are available in the respective course syllabus: Thematic Laboratory I (UAM-C, 2018b), Thematic Laboratory II (UAM-C, 2018c), Thematic Laboratory III (UAM-C, 2018d) and Thematic Laboratory IV (UAM-C, 2018e).

The existence of the Thematic Laboratories is justified in the ITS undergraduate program (UAM-C, 2018a), where it is specified in its general objectives that it aims to: a) train professionals with a solid background in information technologies and systems, with a good understanding of the problems of the organizations, with communication and group work skills and with a clear awareness of the importance of interdisciplinary work and development of computational solutions that support the sustainable development of society; b) from the strictly technical point of view, the graduates will have a solid background in computing fundamentals, with the ability to translate the requirements of the user areas of the organizations where they work, in terms of information systems design and computing infrastructure needed, elaboration of specifications for the development and installation of systems and equipment, as well as to operate systems, provide maintenance and plan together with the user areas the new generations of systems and technologies (UAM-C, 2018a). 
It can be seen that thematic laboratories contribute to the achievement of both general objectives of the ITS undergraduate program. From the first objective, the thematic laboratories should promote "... communication, group work, and awareness of the importance of interdisciplinary work...". The second objective is also fulfilled with these courses, since they promote ".. the ability to translate the requirements of the user areas of the organizations where they work, in terms of information systems design and computing infrastructure, elaboration of specifications for the development and installation of systems and equipment..." (UAM-C, 2018a).

The thematic laboratories are integrator courses, which should allow students to live an experience as close as possible to their professional practice, incorporating their knowledge and skills to solve problems of a specific area or project. In addition, they must develop teamwork skills by project; resolution of clear objectives; responsibility and creativity to solve allocated tasks and problems; capacity for oral and written communication, through presentations and project documentation, respectively.

\section{Content, Conduction and Evaluation of the Laboratories}

The thematic laboratories do not have any seriation, which means that any student of the ITS undergradute program can register to any of them without needing to have attended any other course. The absence of seriation has a double origin: a) the educational model of the UAM-C (Fresán et al., 2015; Fresán \& Outón, 2016), where it is established that the curricular structure must be flexible and centered on the student; and b) the nature of the thematic laboratories, which assume a heterogeneous and interdisciplinary working group, so that the students are expected to have different profiles within the work team, adjusting to the role that each one will play throughout the project. It should be noted that this situation is observed in the four courses that comprise the laboratories; due to this flexibility, it is even possible for a student to take these courses in any order.

The content of the thematic laboratories does not correspond to a series of topics that will be covered throughout the course, as it is normally the case in other courses, but it is a sequence of stages that will be carried out throughout the project to be developed in the course, such as the following: 1) introduction to the topic of the laboratory; 2) presentation of the general project and composition of the working groups; 3) definition of objectives and scope of the project for each group; 4) definition of the work plan for each group; 5) development of activities based on the work plan; 6) weekly progress tracking; 7) presentation of results; and 8) conclusions and perspectives. This content is generic enough to address any type of project: an application for industry, a software program or application for a small business, a research project, etc. It is important to note that the incorporation of ICT in the thematic laboratories is present in several of the stages described above, mainly in those related to the activities of the development and monitoring of the project.

Regarding the guidance of the teaching-learning process for these courses, the teacher is the one in charge of defining the role, topic and scope of the project to be developed in the laboratory. Once the project has been defined, specific roles, objectives and responsibilities are allocated to each of the students, not only considering their level of competence, but also their interests and availability to learn. In this way, it is necessary to make an exploratory evaluation of the students in order to detect their interests, knowledge and skills, which will directly impact the development of the project. This evaluation must be done before the allocation of roles.

The authors of this paper have conducted these laboratories using the following elements: a) topic exhibitions by the teacher, which are carried out at the beginning of the course when an introduction is given to the topic of the laboratory; b) resolution of applicative cases, which is a modality that fosters creativity and innovation of the student to solve real problems; c) collaborative or team work and group discussion, promote communication between the project members and are fundamental activities to achieve the general objective of the degree, in addition to being in accordance with the educational model of the UAM-C: the student must be an active participant in the teaching-learning process (Fresán et al., 2015); d) job reports to translate the requirements, analysis, design and implementation of the project into written documents; e) oral presentations, to show the progress of the different stages of the project, either individually or through the groups defined in the project.

Regarding the ways of evaluation, in the experiences they have had with the thematic laboratories, the authors have carried out four types of evaluation, weighted according to the teacher's criteria: a) written reports of the work carried out, which reflect the different stages of the project, such as the requirements survey, analysis, design and implementation of the project; b) periodic evaluations of the compliance of each stage, which include daily or weekly monitoring logs, used to measure the progress of the activities with respect to the work plan established at the beginning; c) participation in the practical sessions, which makes it possible to observe the enthusiasm and particular contribution of the students when carrying out each of their allocated activities; and finally, d) the project's presentation at the end of the course is in group and includes the project as a whole, in 
which all students participate according to their roles and activities designated in the work plan; additionally, presentations have been carried out in the middle of the term to measure their progress up to that moment.

\section{Projects and Topics Addressed in the Laboratories}

In order to illustrate the types of projects and the nature of the topics that have been addressed in the thematic laboratories, this section provides a list of four projects that the authors have supervised. Each project includes its name, topic and a brief description.

1) Project: Web system for administration of continuing education courses. Topic: Management systems. Description: This project was developed to automate the administration of continuing education courses taught in the three academic departments of the Division of Communication Sciences and Design (DCCD) of the UAM-C. The series of continuing education courses taught at DCCD are of a wide variety of subjects, with duration, number of participants, requirements and variable prices.

2) Project: Web system for ticket sales for auditorium events. Topic: Electronic commerce systems. Description: This project was developed to automate the sale of tickets for the events of a fictional auditorium through the Internet. The auditorium provides the public with events of different types, such as concerts of singers and musical groups, plays, dance, conferences, and other entertainment events. The prices of the tickets vary according to the type of event.

3) Project: Online store for Oaxacan handicraft. Topic: Electronic commerce systems. Description: This project was developed to provide an online store where articles from a fictitious Oaxacan craft center can be offered through the Internet, as a strategy to sell Oaxacan handicrafts nationally and internationally. The craft center is dedicated to the sale of handicrafts from the eight regions of the State of Oaxaca and only sells its handicrafts directly in its facilities and by orders by phone or email.

4) Project: Web system for the administration of social service. Topic: Management system. Description: This project was developed to automate the administration of the social service proposals available at the UAM-C through the Social Service Office. Among the required functionality developed is the registration of social service proposals, the registration of new institutions that offer such proposals, the application of the student in any of the proposals, among others.

The following section describes the whole process carried out in terms of conducting a thematic laboratory with students of the ITS undergraduate program for the development of the first of the mentioned projects, in order to share the experience of the authors in the incorporation of different ICT in each of the stages of the project.

\section{Experience in the Conduction of a Thematic Laboratory}

The project described in this section shows the experience of the authors in the conduction of a thematic laboratory. The project developed during the laboratory was a web system for administration of continuing education courses, which is representative enough of the potential of the thematic laboratories in the training of the students of the ITS undergraduate program, by promoting their autonomy with the use of the ICT, involving them in perfecting their skills for the analysis and use of information, and fostering self-learning through situations and experiences close to their professional practice. At the same time, the thematic laboratories are good examples of situated learning (Lave \& Wenger, 2003; Díaz Barriga, 2006), where the idea is to create meaning from the real activities of daily living, which in this case the project close to professional practice is something very close to reality. In addition, with the development of this project students were encouraged to judge different products, as it allowed them to identify problems and find their solutions, become familiar with programming languages and develop their oral and written communication skills during the presentation of the project. Finally, this project aimed to stimulate interest in the problems of other members of the work team, since each of them took different roles within the project. It was also sought to promote coexistence and the solution of collective situations, in order to develop attitudes of responsibility through teamwork and allocation of tasks.

\subsection{Initial Stage of the Project}

During the first three weeks of the term, students were given an introduction to the topic of the laboratory; in this case it was about information management systems in organizations. The project was presented and interviews were held with each student to identify their strengths, weaknesses and interests, based on the courses they had studied so far and on the school projects in which they had previously worked. Work teams were formed and roles allocated to the students, according to the competences and interests identified in the interviews. It should be noted that two of the twelve students who enrolled in the course lacked of programming skills, so it was decided to integrate each of them into teams where the programming of the system was not involved, leaving the teams as follows: a) the analysis team was composed of three members, including one of the students who lacked 
of programming knowledge; b) the design team was made up of two students; c) the implementation team was composed of five members, all of them with diverse knowledge and experience in the programming of school projects, which they were acquiring throughout the courses that they had already completed so far; and d) the test team was in charge of two members, one of them was the other student with no programming experience.

Once the work teams were formed, it was briefly explained the basic process of software development that we would adopt to carry out the project throughout the term, OpenUP (2018), which is a unified process that is applied to the development of projects with incremental iterations within a well-structured life cycle. This unified process is based on the Rational Unified Process, RUP (Kroll \& Kruchten, 2003); however, OpenUP was chosen, since it is widely used in the software development industry, so it was considered very important that the students had an approach to it. It should be noted that several of the students were motivated because of the fact that this development process is used by large companies, which promoted their interest to delve deeper into the knowledge of this through the documentation provided on the OpenUP web site.

The activities that were defined for the work teams in this stage are described below. According to the OpenUp methodology, the analysis team was in charge of a) gathering initial requirements with the client, in this case with the coordinator of the Continuous Education Area of the DCCD; b) defining a document with the technical vision of the project; c) developing a project plan; d) developing a diagram of use cases; and e) defining the main scenarios of the use cases. The design team was in charge of developing the interface model of the system, which refers to the proposal of visualization of the web pages that the user of the system would use; in order to accomplish its tasks, the team members were in constant communication with the analysis team to determine what the web pages would contain, based on the requirements gathered. The implementation team was responsible for evaluating various tools and technologies to implement the required system, among which they had to evaluate and choose a web technology to develop the project, programming languages, a web or application server, a database management system (DBMS), and an integrated development environment (IDE) for editing their files. Finally, the test team was mainly dedicated to the specification of initial test cases, based on the requirements gathered by the analysis team, which were captured in use cases.

The technological incorporation in this academic experience was present from the initial stage of the project, since a wide variety of ICT were evaluated and used to carry out the various activities that were allocated to each team. Some of them are described below.

To register the work plan and follow up on each of the activities that were allocated to the members of the work teams, Gantt Project (Thomas, 2018) was used, which is a free software tool that makes it possible to manage and monitor projects through various interactive graphics that allow to visualize a series of important data in the project. Specifically, students used Gantt Project to create Gantt charts that represent the expected duration of the activities throughout the project; resource diagrams were also created, which allowed to represent the human resources that participated in the project, with information about their roles, a fictitious cost per hour and their allocation of activities.

A version control system was installed, called Apache Subversion (2018), used to manage the versioning of all the shared files in the project, such as the technical vision documents, the document of the project plan, administrative documents and source code files written in different languages that were created in the following stages of the project. This tool was very useful and facilitated the work of the following project stages, when the system was developed, since normally in a project of this nature there are files that must be edited concurrently by two or more team members, which was handled by Apache Subversion.

Use case diagrams were generated with StarUML (2018), which is a software tool that allows creating the Unified Modeling Language (UML) diagrams (Booch, Rumbaugh, \& Jacobson, 2005). StarUML also allowed students to generate the collaboration and sequence diagrams, which were elaborated in the following stages of the project. It should be noted that two other tools for modeling diagrams were evaluated, ArgoUML (2018) and Dia (2018); however, the students adapted better to the StarUML interface, so this was the one they used throughout the project.

The design of the system interface was carried out in the Balsamiq Mockups software tool (2018), which allowed the design team to draw the system screenshots by dragging and arranging elements, quickly achieving interfaces that described the needs of the system more clearly, and validating them with the analysis team and with the client.

The implementation team, composed of five members, was divided to investigate and evaluate web technologies to develop the project, programming languages, web servers, application servers, DBMS and IDE. In the case of web technology, they decided to use Java Server Pages (JSP), Java as the programming language, and NetBeans 
(2018) as the IDE, which allowed them to develop the web application in the following stages of the project. The web server used was Apache Tomcat (2018), designed to host web applications that use Java and JSP as their web technology. Regarding the storage of the system information, it was decided to use MySQL (2018) as DBMS, which allowed to create the database for the system in the following stages of this project, and thus execute statements of the Structured Query Language (SQL), both of the Data Definition Language (DDL), and of the Data Manipulation Language (DML).

In the case of the test team, given that its main activity was to find errors (defects, failures or incidents), it was essential to have a software tool that allowed them to record, report, manage and track these errors. Although initially they had chosen to use Excel to record and track errors and communicate them via e-mail to the rest of the members involved in the project, the authors of this paper asked them to think of a more robust mechanism that made the handling of errors easier, given that the project would grow and progress in the following stages. The team undertook the task of searching and evaluating some tools that would allow the basic functions of error tracking: reports and graphs, allocation of errors, progress of the error solutions, history and storage. Bugzilla (Weissman, 2018) was the error tracking tool that they decided to use throughout the project because its interface was very simple to understand and navigate, although they also evaluated Lean Testing (2018) and Mantis Bug Tracker (2018).

\subsection{Elaboration Stage of the Project}

According to OpenUP, the unified process that was adopted at the beginning of the project, the elaboration stage lasted three weeks. During them, only an iteration was achieved and progress was made in the activities established in the project plan. The activities were carried out according to the work teams, where collaboration was observed among the members within the teams to carry out their work, as well as collaboration with members of the other teams in those activities where there were certain dependencies in the work.

The analysis team progressed in the refinement of the use cases identified in the initial stage, elaborated new use cases derived from their meetings with the client, elaborated collaboration and sequence diagrams and updated the project plan documents. The design team continued with the preparation of interfaces and met several times with the client to perform the corresponding validations of the interfaces previously developed. The implementation team began the development of the project with the technologies and tools defined in the initial stage, and based on the artifacts generated by the analysis and design teams (use cases, collaboration diagrams, sequence diagrams, interfaces). Finally, the test team continued with the preparation of the test cases, based on the use cases generated by the analysis team, and carried out the unit tests of the first web pages developed by the implementation team.

The elaboration stage continued making use of the different ICT discussed in the initial stage of the project, which were fundamental for the achievement of the planned activities. Although the use of ICT was a slow process of appropriation, by the end of this stage a better understanding of the project could be visualized, as could be seen in the oral and written presentations made by the students. It should be noted that most of the members of the group showed enthusiasm and commitment in carrying out the activities that were allocated to them, as well as a willingness to learn from their peers, who had to perform different tasks because of the nature of their roles. At the same time, most of the members of the project showed willingness to share the knowledge they acquired in their respective investigations.

\subsection{Construction Stage of the Project}

The second half of the term was used for the construction stage, according to OpenUP. Two iterations of three weeks each were carried out, in which there were weekly reviews of the progress made in the project activities. Once again, all the activities included in the project plan were followed up. Each team continued with the generation of their respective artifacts using the ICT described above, whose management by the students was already more appropriate. The communication between the members of the project was strengthened inside and outside of the teams. There was the disadvantage that two students left the course, so they had to adjust and reallocate the remaining activities. This incident had repercussions on the scope of the project, which was shortened. However, this allowed to reflect the dynamics of the projects carried out in professional practice, where the rotation of staff is a factor to be considered. From the teaching perspective, this fact was noted and it was even a learning opportunity for students, because it demonstrated the richness of the thematic laboratories and their particular dynamics.

Given that the duration of the project was twelve weeks and there were delays in activities for various reasons, it was not possible to reach the stage of transition that OpenUP establishes, which is the stage where a deliverable 
with all its functionality is prepared for use by the client. However, the developed project was in an acceptable state of operation, being able to be used despite the fact that the functionality planned was not finished.

In the twelfth week of the term, the final presentation of the project by the students was made, where the client and some ITS teachers were invited, who asked some questions to the students about the process carried out to develop the project and their experience. It should be noted that most of the students said they were satisfied with the whole process that took place, the resulting project, the activities carried out, the ICT they used to carry out their activities, the learning acquired, as well as the communication they had with their classmates. The following figures show some screenshots of the system implemented in the thematic laboratory.

Figure 1 shows a screenshot of the home page, where services (courses, workshops or diploma courses) offered by the Continuing Education Office are illustrated. The interface shows that it is possible to enter the system either as a student to enroll in a specific course, workshop or diploma, or as an administrator to register a service or use other functionality.

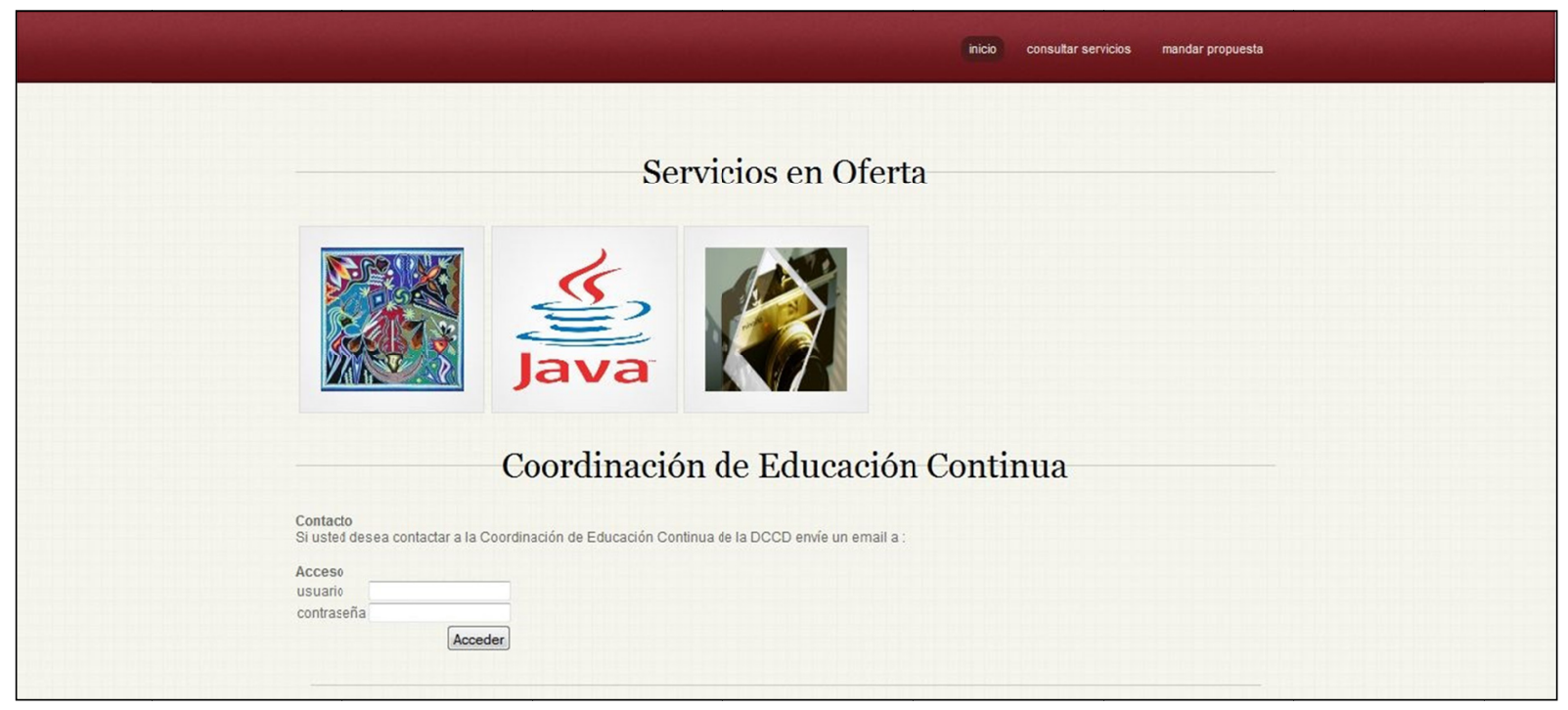

Figure 1. Home page of the continuous education system

Figure 2 displays a screenshot of the web site with a list of proposals for continuing education courses, which have been registered by the administrator. The interface shows that it is possible to register courses, workshops or diploma courses; the instructors who teach them; the title of the course, workshop or diploma; and there are options to view, edit, send by email and delete them.

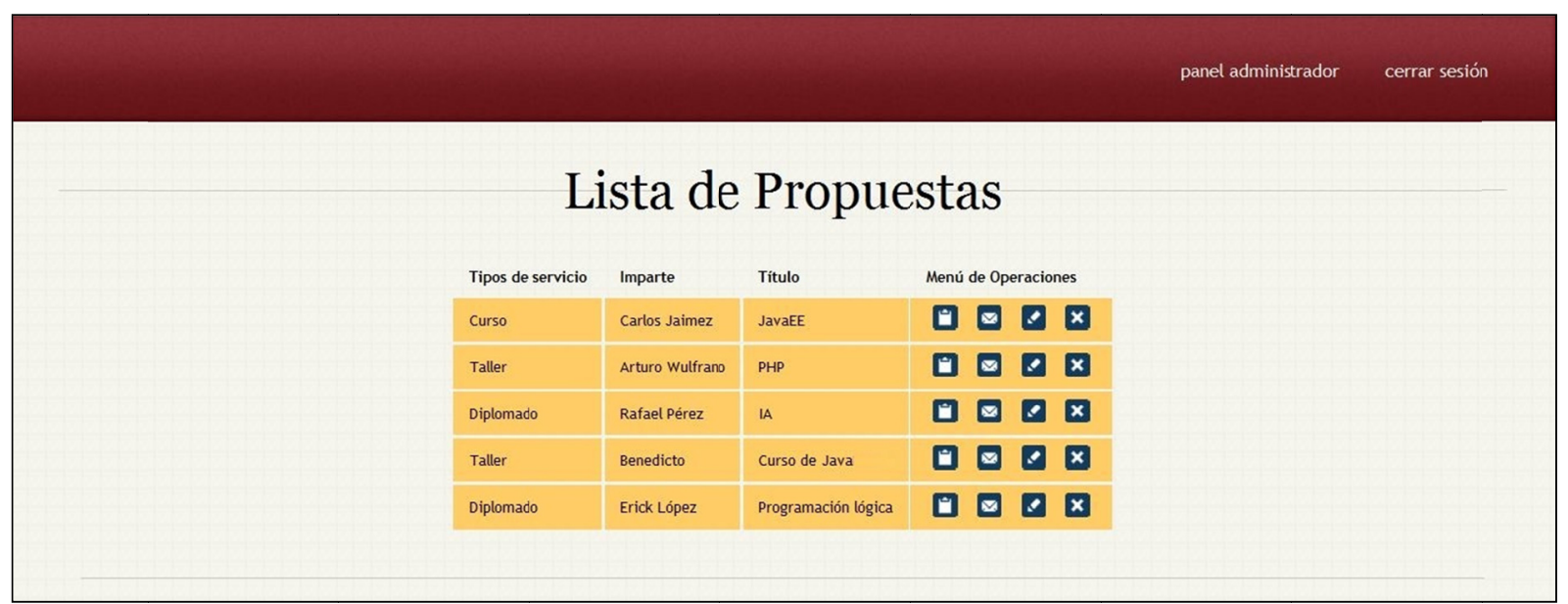

Figure 2. Web page that shows a list of courses, workshops and diploma courses 
Figure 3 shows a screenshot of a web page that allows to view the details of a course, workshop or diploma course, where it is also possible to modify all the information displayed: type of service, name, instructor, audience, description, start and end dates, duration in hours, days of the sessions, time, place, image for the service and agenda.

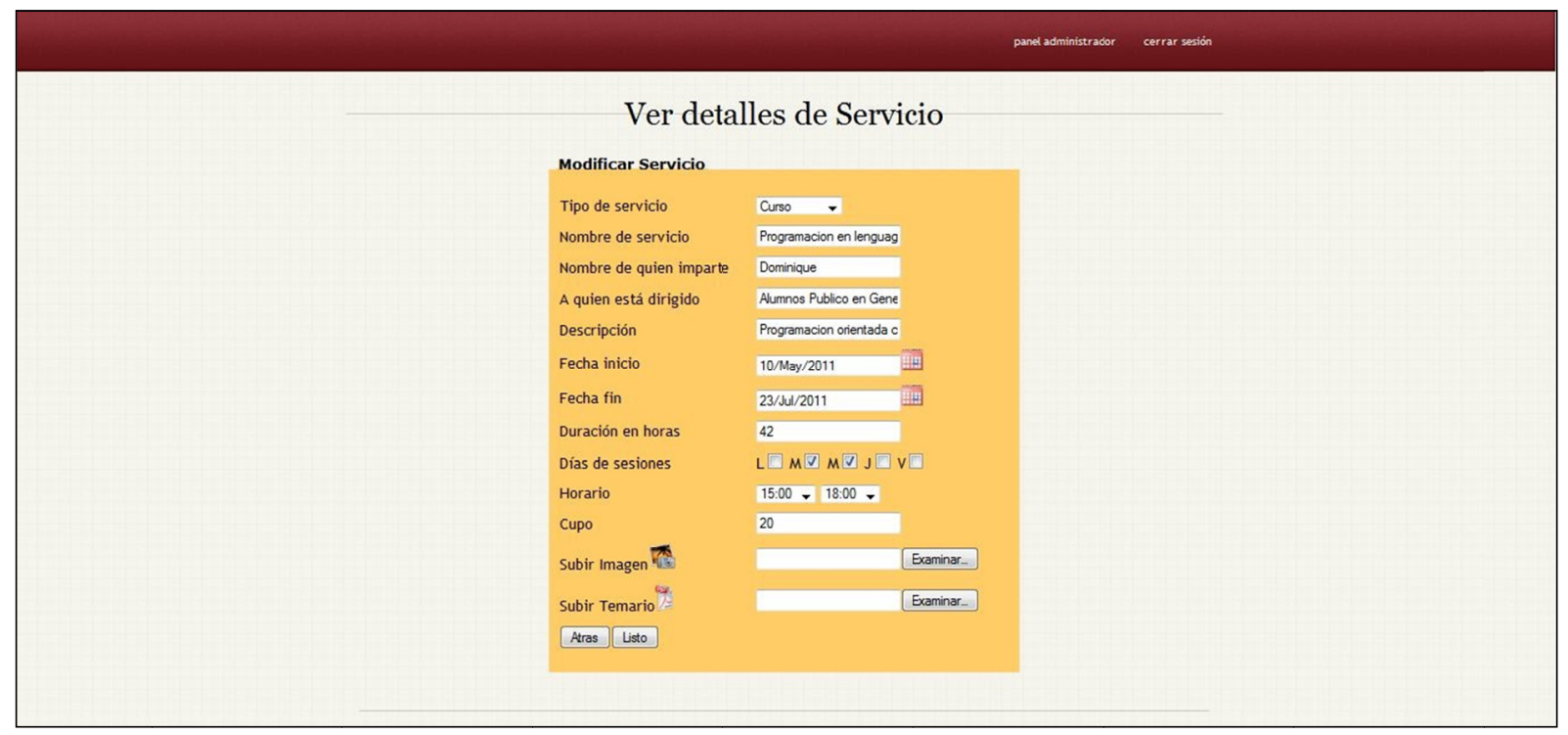

Figure 3 . Web page that shows the details of a course and allows to modify it

In Figure 4 there is a screenshot of the web page that shows the system options for an administrator user: the option add service allows registering a course, workshop or diploma; the service modification option allows to modify any of the services that have already been registered; the option to review proposals is used to visualize and modify the proposals for continuing education services that have not been approved yet; and finally, the history option allows showing all the courses, workshops and diploma courses that have been taught.

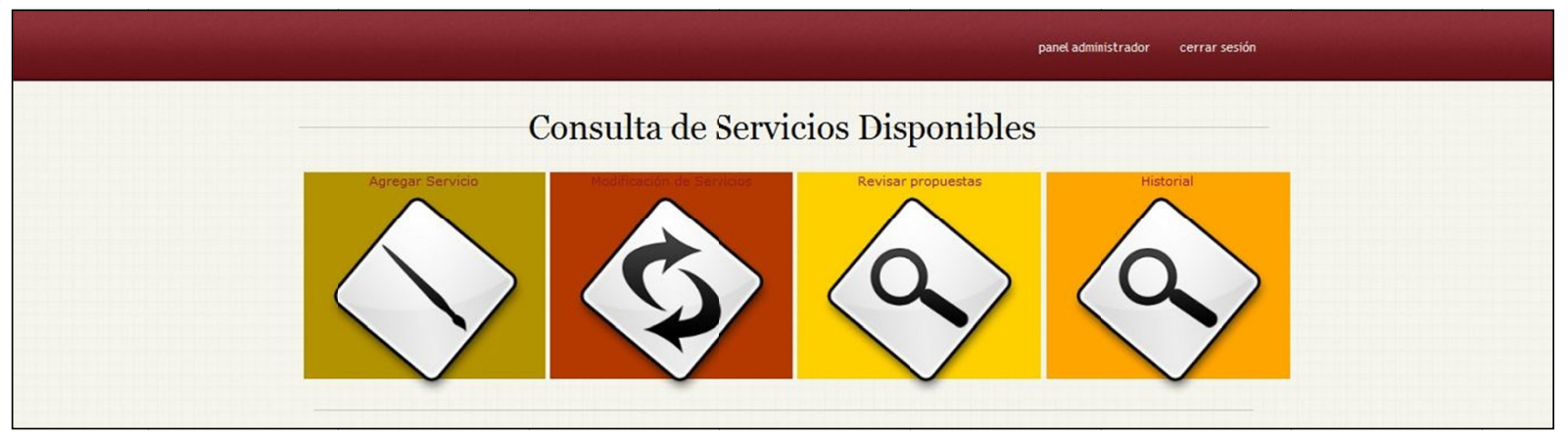

Figure 4. Web page that shows the system options for an administrator

The screenshots presented are only some examples of web pages that compose the system that resulted as the product of the thematic laboratory.

\section{Conclusions}

This paper presented an academic experience that incorporated ICT in the teaching-learning process in the context of one of the courses called thematic laboratories, which belong to the ITS undergraduate program. Thematic laboratories, due to their features, offer the opportunity to work with heterogeneous groups of students. One of its objectives is to achieve an experience close to the professional practice that students will find when they graduate, generally through the development of a software project or an application to solve a problem in a specific area belonging to a real or fictitious organization. In the process of conducting a thematic laboratory, 
given the aforementioned conditions, the incorporation of ICT tools was necessary and was of great help for the management of both the activities of the working groups, as well as their follow-up.

The example shown in this paper corresponds to the development of an application for the Continuous Education Office of the DCCD, for which the project web system for administration of continuing education courses was developed. The results of this experience were satisfactory, because they helped to promote self-learning and autonomy among students, with the use of ICT through a project based on a situation close to the student's future professional practice. In summary, in the experience conducting the thematic laboratory:

- It was possible to organize students according to their profiles in work groups with different roles, allocating specific and differentiated tasks according to the needs of the project defined by the teachers, their interests and personal skills. It should be noted that students who did not have programming skills were included in the groups, adapting them to the remaining activities that were also important for the elaboration of the project.

- The course was divided into several stages, according to OpenUp, a unified process of software development used by several industry organizations, which motivated the students from the beginning to study and apply the methodology. Another benefit of OpenUp is that due to the development cycle it implements, it makes it feasible to use it in the context of the duration of the term, since it is incremental, which provides successive revisions of the final product in different stages of its development. This experience was a successful example of the inclusion of ICT in teaching, which transcends software tools, extending its notion to methodologies and development processes.

- Two students left the course during the evolution of the project. This forced to restructure the work teams from the teaching side and far from being a disagreement, it served to exemplify the fact that in the professional practice the rotation of staff is a factor with which every organization must contend, emphasizing the importance of planning and the clear division of tasks and responsibilities.

- It was possible to involve students in the definition of the ICT tools suitable for the development of the project, making a comparative and selective process among the different available options. The use of ICT in the different stages of the course was successfully promoted and the central objective of the thematic laboratory was fulfilled, in accordance with the syllabus, that is: the inclusion of the students in its own teaching-learning process, in this case, around the development of a project with the features of one similar to those found in the professional practice.

- Although the development of the project was not completed as planned, at the time of the conclusion of the course, its final state was close to having full functionality, achieving an operational project that solved the main objectives defined at the beginning of it. The students were satisfied with the experience of the course, and during its presentation some teachers agreed that the work done was relevant both as a software development project and for the objectives of the course. It was confirmed that the strategy followed by the students and the teachers, although perfectible, was successful.

Finally, the thematic laboratories are courses very particular in their features and objectives. Its complexity has a double challenge for the teacher: work with heterogeneous groups in skills and interests to achieve a project; and propose a project that is similar as much as possible to professional practice. Despite this, the experience shown here confirms that thematic laboratories can lead to conductions that meet the objectives of the course, and benefit from the use of available ICT tools to promote self-learning and autonomy of the students.

\section{References}

Apache Subversion [software]. (2018). Wakefield. MA: Apache Software Foundation. Retrieved from http://subversion.apache.org

Apache Tomcat [software]. (2018). Wakefield. MA: Apache Software Foundation. Retrieved from http://tomcat.apache.org/

ArgoUML [software]. (2018). Brooklyn, NY: Software Freedom Conservancy. Retrieved from http://argouml.tigris.org/

Balsamiq Mockups [software]. (2018). Sacramento, CA: Balsamiq Studios. Retrieved from https://balsamiq.com/products/mockups/

Booch, G., Rumbaugh, J., \& Jacobson, I. (2005). The Unified Modelling Language User Guide. Boston, Massachusetts, USA: Addison-Wesley Professional.

Dia [software]. (2018). The Dia Developers. Retrieved from http://dia-installer.de 
Díaz Barriga, F. (2006). Enseñanza situada: Vínculo entre la escuela y la vida. México: McGraw-Hill.

Fresán, M., García, A., Aparicio, F., Tristán, F., García, A., Olsen, M., Moreno, T., Rodríguez, C., Solano, E., Espinosa, M., Ramey, J., Fabre, V., \& Hernández, G. (2015). El modelo educativo de la UAM Cuajimalpa: 10 años de vida. México: UAM.

Fresán, M., \& Outón, M. (2016). Reflexiones sobre el Modelo Educativo de la UAM-C. México: UAM. Retrieved from http://web.cua.uam.mx/files/reflexiones\%20modelo\%20educativo.pdf

Kroll, P., \& Kruchten, P. (2003). Rational Unified Process Made Easy: A Practitioner's Guide to the RUP. Boston, MA: Addison-Wesley.

Lave, J., \& Wenger, E. (2003). Situated Learning: Legitimate Peripheral Participation. Cambridge, United Kingdom: Cambridge University Press.

Lean Testing [software]. (2018). Santiago, Chile: Crowdsourced Testing SpA. Retrieved from https://leantesting.com/

Mantis Bug Tracker [software]. (2018). MantisBT Team. Retrieved from http://www.mantisbt.org/

Metropolitan Autonomous University, Cuajimalpa Campus (UAM-C). (2018a). Information Technologies and Systems Undergraduate Program. México: UAM. Retrieved from http://hermes.cua.uam.mx/archivos/PlandeEstudioTSI.pdf

Metropolitan Autonomous University, Cuajimalpa Campus (UAM-C). (2018b). Syllabus of the Thematic Laboratory I. Information Technologies and Systems Undergraduate Program. México: UAM. Retrieved from http://hermes.cua.uam.mx/files/tsi/450207_laboratorio_tematico_1.pdf

Metropolitan Autonomous University, Cuajimalpa Campus (UAM-C). (2018c). Syllabus of the Thematic Laboratory II. Information Technologies and Systems Undergraduate Program. México: UAM. Retrieved from http://hermes.cua.uam.mx/files/tsi/450215_laboratorio_tematico_2.pdf

Metropolitan Autonomous University, Cuajimalpa Campus (UAM-C). (2018d). Syllabus of the Thematic Laboratory III. Information Technologies and Systems Undergraduate Program. México: UAM. Retrieved from http://hermes.cua.uam.mx/files/tsi/450216_laboratorio_tematico_3.pdf

Metropolitan Autonomous University, Cuajimalpa Campus (UAM-C). (2018e). Syllabus of the Thematic Laboratory IV. Information Technologies and Systems Undergraduate Program. México: UAM. Retrieved from http://hermes.cua.uam.mx/files/tsi/450217_laboratorio_tematico_4.pdf

MySQL [software]. (2018). Redwood Shores. CA: Oracle Corporation. Retrieved from https://www.mysql.com/

NetBeans IDE [software]. (2018). Redwood Shores. CA: Oracle Corporation. Retrieved from https://netbeans.org/

OpenUP [software]. (2018). Ottawa, Canada: Eclipse Foundation. Retrieved from https://www.eclipse.org/epf/openup_component/openup_vision.php

StarUML [software]. (2018). Daejeon, Republic of Korea: MKLab Co. Retrieved from http://staruml.io/

Thomas, A. (2018). Gantt Project [software]. Marne la Vallée, France. Retrieved from https://www.ganttproject.biz/

Weissman, T. (2018). Bugzilla [software]. Palo Alto, CA. Retrieved from https://www.bugzilla.org/

\section{Copyrights}

Copyright for this article is retained by the authors, with first publication rights granted to the journal.

This is an open-access article distributed under the terms and conditions of the Creative Commons Attribution license (http://creativecommons.org/licenses/by/4.0/). 